\title{
Design, Simulation, Prototyping and Experimentation of Planar Micro- strip Patch Antenna for Passive UHF RFID to tag for Metallic Objects
}

\author{
Tashi ${ }^{1}$, Mohammad S. Hasan ${ }^{2}$, and Hongnian $\mathrm{Yu}^{3}$ \\ ${ }^{1}$ Department of Electronics and Communication Engineering, College of Science and Technology, Rinchending, \\ Phuentsholing, Bhutan \\ ${ }^{2}$ Faculty of Computing, Engineering and Technology, Staffordshire University, Stafford, Staffordshire, ST18 0AD, UK \\ ${ }^{3}$ Computer Science and Informatics, Bournemouth University, Poole House P316, Talbot Campus, BH12 5BB, UK \\ ${ }^{1}$ tashi.cst@ rub.edu.bt, ${ }^{2}$ m.s.hasan@staffs.ac.uk, and ${ }^{3}$ yuh@bournemouth.ac.uk
}

\begin{abstract}
Passive radio frequency identification (RFID) system operating in the ultrahigh frequency (UHF) band ranging from $860 \mathrm{MHz}$ to $960 \mathrm{MHz}$ is getting considerable attention in the recent years as it provides a long reading range, high data rate, and small antenna size. However, the passive UHF RFID tag does not work when it is directly mounted on metal objects. The performance of the passive UHF RFID tag is becoming increasing important for tagging metallic objects, in particular, in the warehouse applications. In this paper, a micro-strip patch antenna is proposed for the passive UHF RFID systems to tag metallic objects. The proposed design of the micro-strip patch antenna is supplemented by simulation and reading range measurement results. The prototype antenna measurements show a maximum reading range of $4.5 \mathrm{~m}$ and a reliable reading range of $1.89 \mathrm{~m}$ on metallic objects. The experimental results show that the prototype micro-strip patch antenna works very well on the metallic objects.
\end{abstract}

Keywords - UHF RFID system, Passive tag, Tag antenna, Micro-strip patch antenna.

\section{INTRODUCTION}

Radio frequency identification (RFID) technology [1] is growing a tremendous demand in the supply chain management systems. RFID is an automatic and pervasive identification technology for collecting and gathering data from a tagged item. The data is stored in the mobile device called tag which is embedded in cardboard boxes, ID card, airline baggage strip, passport, and clothing tags. When the tag comes in the reader's reading zone, the data is collected by the reader without any need of physical contact. The data in the tag may be the identification number, location information, or specification of product such as price, brand, and date. Unlike bar code technology, the RFID technology does not require line-of-sight and reads longer distance [2]. Such advantages help the supply chain to operate very fast and efficiently.

Recently, a passive RFID system that operates in the UHF band from 860 to $960 \mathrm{MHz}$ is getting considerable attention in many applications [3]. As the passive tag is very cheap due to the absence of an onboard battery, it provides longer reading range, high data rate, and small antenna. A label-type dipole antenna is commonly used as a tag antenna and is printed on a very thin film at low cost $[4,5]$ to reduce the overall cost of the tag. However, the papers [6] and [7] have reported that the passive tags undergo a serious performance degradation when it is mounted on metallic objects. The metallic objects short-circuit the tag antenna and changes the performance parameters such as radiation pattern, antenna impedance, gain and bandwidth. As a result, the tag can become unreadable to the reader within the normal reading zone. On the other hand, there are still increasing demands on RFID technology in the supply chain application for tagging metallic objects since most of the items in a warehouse are made of metal or encased in metallic boxes or containers.

This problem may be solved by using an active RFID tag, but it will be very costly. An alternative solution would be keeping enough separation gaps between the tag and the metallic surface or designing a tag antenna that can operate using the ground plane. Micro-strip patch antenna and planar
inverted-F antenna (PIFA) are attractive choices as the both antennas uses the ground plane. The RFID tags have employed using the micro-strip patch antenna in [8-15] and the PIFA in [16-18]. However, all these tag antenna designs have an electrical connection between the radiating element and the ground plane (e.g. [10]), and an electrical connection between the feeding line and the ground plane (e.g. [14]). This leads to the cross-layered construction of tag antennas. In PIFA design, the tag antenna has multilayered construction (e.g. [17]). Such designs have complex and costly antenna structure, but most of the RFID applications demand the tag to be smaller in size and of low cost. To achieve this, the tag antenna should be constructed with a completely planar structure without any cross or multilayered construction.

In this paper, a complete planar micro-strip patch antenna is proposed for a passive UHF RFID tag that can be used for tagging metallic containers or boxes in the warehouse environment. The fundamental characteristic of the proposed antenna design is that the radiating element (patch) is suspended above the ground plane without any electrical connection between the radiating element and the ground plane. This eliminates the cross-layered and multilayered construction without compromising its performance.

The rest of the paper is organised as follows. Section 2 discusses the proposed antenna design. Section 3 presents the simulation set-up and results of the proposed antenna. Section 4 explains the prototype development and the experimentation of the reading range measurement. Finally, section 5 presents the conclusion with some future work directions.

\section{THE PROPOSED ANTENNA DESIGN}

\subsection{Application of the Proposed Antenna}

The proposed micro-strip patch antenna for a passive UHF RFID tag is considered to operate in the UK and Europe warehouse environment for tagging metallic boxes or containers [15], [19]. The proposed antenna should be easily tuneable from $865 \mathrm{MHz}$ to $867 \mathrm{MHz}$ range for the UK and 
Europe UHF RFID frequency band. The operating frequency $\left(f_{0}\right)$ of the proposed antenna is selected as $866 \mathrm{MHz}$.

\subsection{A UHF RFID Tag Chip}

A passive UHF RFID tag consists of an antenna and a chip. The UHF RFID tag antennas are designed based on the input impedance of the tag chip. For the proposed design, the Alien Higgs-3 [20] is selected as it is widely used in the industry and is commercially available in the market. The Alien Higgs-3 is an integrated single chip for EPC (Electronic Product Code) Class 1 Generation 2 RFID tag manufactured by the Alien Technology. The Alien Higgs-3 exhibits an input impedance of $Z_{C}=(31-j 212) \Omega$ at 866 $\mathrm{MHz}$ operating frequency and requires a minimum of -14 $\mathrm{dBm}$ power to turn on the chip. In order to deliver the maximum power from the antenna to the chip, the input impedance of the antenna, $Z_{\mathrm{A}}$ should be complex conjugately matched to the chip impedance, $Z_{\mathrm{C}}$ (i.e. $Z_{\mathrm{C}}=Z_{\mathrm{A}}{ }^{*}$ ). Therefore, the proposed antenna design should have an input impedance of $Z_{\mathrm{A}}=(31+\mathrm{j} 212) \Omega$.

\subsection{The Tag Antenna Substrate Material}

For low cost, easy installation and availability in the market, the Printed Circuit Board (PCB) manufactured by the KELAN [21] is chosen as the substrate for the proposed antenna. The PCB is made from double sided copper clad Epoxy Glass Flame Retardant Type-4 (FR4) with thickness (h) of $1.6 \mathrm{~mm}$, relative permittivity $\left(\varepsilon_{\mathrm{r}}\right)$ of 4.9 , loss tangent $(\delta)$ of 0.025 and the copper clad thickness $\left(t_{\mathrm{a}}\right)$ of $0.0356 \mathrm{~mm}$. The one side of the copper is used as the radiating element and other side of the copper is used as the ground plane of the proposed antenna.

\subsection{The Proposed Antenna Structure Design}

Figure 1 shows the basic structure of the proposed antenna. The proposed micro-strip patch antenna has three layers. The top layer is the radiating element (i.e. antenna trace or patch), middle layer is the antenna substrate, and bottom layer is the antenna ground plane. The radiating element has length $(L)$ of $78 \mathrm{~mm}$ and width $(W)$ of $50 \mathrm{~mm}$. The ground plane has length of $86 \mathrm{~mm}$ and width of $58 \mathrm{~mm}$. The variation of width $(W)$ vs return loss for fixed length is shown in the simulation result section. The proposed antenna is designed for the selected substrate height $(h)$ of $1.6 \mathrm{~mm}$ based on the PCB manufacturer specification.

The two small slots are made on the radiating element which are called window having the length, $L_{\mathrm{w}}=6 \mathrm{~mm}$ and width, $W_{\mathrm{w}}=2 \mathrm{~mm}$. The windows are used for fine tuning of the resonance frequency of the proposed antenna. By varying $L_{\mathrm{w}}$ and $W_{\mathrm{w}}$ with small step, the resonance frequency of the proposed antenna is tuned to the desired operating frequency without changing other parameters of the radiating element.

Traditional micro-strip patch antenna is single feed that can be designed as direct feed type or coupled feed type and keeping reference with respect to the ground plane [22]. Such feeding methods require a cross-layered construction like electrical connection between the patch and the ground plane in order to attach the chip to the antenna. To avoid cross-layer, T-match feeding is proposed for this design. The T-match feeding lines are inserted inside the rectangular slot made on the radiating element with the slot length, $L_{\mathrm{s}}=40$ $\mathrm{mm}$ and slot width, $W_{\mathrm{s}}=6 \mathrm{~mm}$. The chip is then directly attached to the T-match feeding lines. This eliminates the electrical connection between the feeding line and the ground plane. The chip location is fixed at the centre of the radiating element (i.e. at the origin of principle $x-y$ plane of the proposed antenna). The RF port-1 of the RFID chip is connected to the radiating element via feed line-1 having length, $L_{\mathrm{fa}}=6.5 \mathrm{~mm}$ and the RF port-2 (i.e. ground) is connected to the radiating element via feed line- 2 having length, $L_{\mathrm{fb}}=32.5 \mathrm{~mm}$. Both feeding lines have width, $W_{\mathrm{f}}=2$ $\mathrm{mm}$. The input impedance of the proposed antenna is tuned by adjusting geometry parameters of T-match feeding lines.

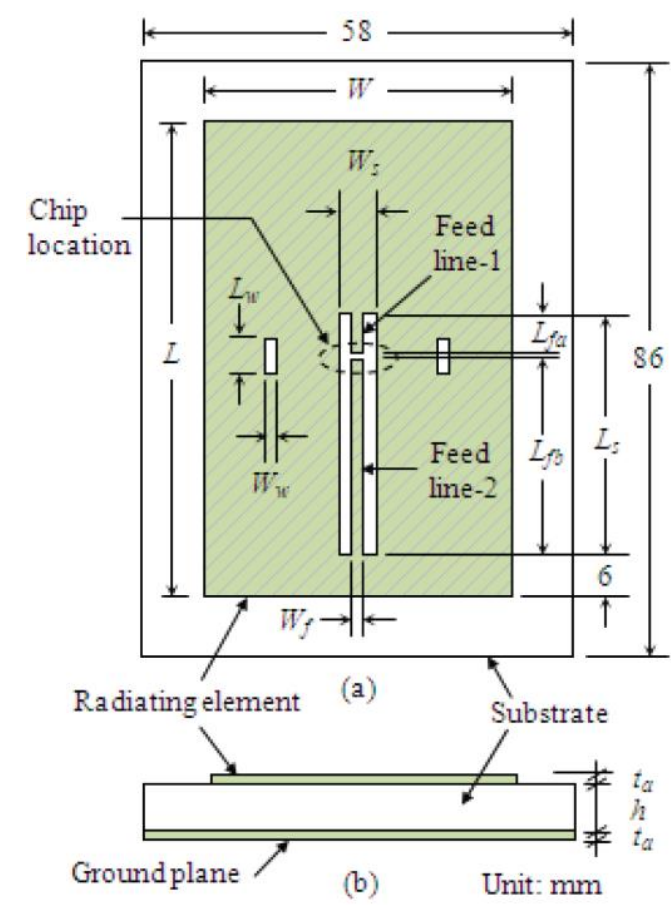

Figure 1: The geometry of the proposed micro-strip patch antenna (a) top view and (b) side view.

\section{SIMULATION SIMMULATION SET-UP AND RESULTS}

\subsection{Simulation Set-up}

The proposed micro-strip patch antenna is designed and simulated in the Sonnet Lite EM simulator [23]. The same model is developed in AWR (Advancing the Wireless Revolution) simulator [24] and simulation results are compared for validation. Both EM simulator works based on the method of moments (MoM).

The Sonnet EM simulation analysis is performed inside a four-sided lossless metal box. This box is divided into the three layers as shown in Figure 2. The top layer is set as the free space, the middle layer as the substrate and the bottom layer as the ground plane. The antenna radiating element is placed on the substrate at the centre of the box. While the four sidewalls provide a perfect ground reference as well as to use Fast Fourier Transform (FFT) to compute all circuit cross-coupling. The sidewalls are set at 1.5 wavelengths (the Sonnet recommended to set one to three wavelengths) from the antenna trace to avoid the effects from the sidewalls. The wavelength of an $866 \mathrm{MHz}$ signal is $346 \mathrm{~mm}$. This gives the box size of $1200 \mathrm{~mm}$ x $1200 \mathrm{~mm}$. The top layer and bottom layer are set at $200 \mathrm{~mm}$ (the Sonnet recommended to set not less than or equal to the half wavelength) which is slightly 
more than half wavelength to avoid the effect of fringing fields (i.e. near field). The middle layer is set at the height of $1.6 \mathrm{~mm}$ with dielectric constant $\left(\varepsilon_{\mathrm{r}}\right)$ of 4.9 and loss tangent $(\delta)$ of 0.025 . The antenna radiating element material is selected as a copper (i.e. same as design) and set as copper thickness $\left(t_{\mathrm{a}}\right)$ of $0.0356 \mathrm{~mm}$ and conductivity of 58000000 siemens per meter.

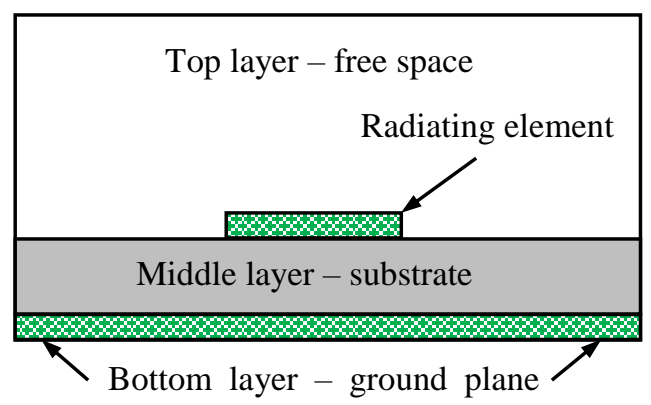

Figure 2: Front view of the simulation set-up for the proposed antenna.

Finally, all the simulations are performed using Adaptive Band Synthesis (ABS) that sweep the frequency from $800 \mathrm{MHz}$ to $1000 \mathrm{MHz}$ which is wider than the UHF RFID frequency band (i.e. $860 \mathrm{MHz}$ to $960 \mathrm{MHz}$ ). This ensures that the whole UHF RFID frequency response can be plotted inside the simulation output for analysis. Once parameter sweep is completed, the Sonnet will plots return loss vs. frequency. The simulation results of the proposed antenna are presented in the following sections.

\subsection{Simulation Results}

\subsubsection{The Optimisation of the Proposed Antenna Width for Selected Length}

From the theoretical calculation of the rectangular micro-strip patch [22], the length and the width are 78.82 $\mathrm{mm}$ and $100.80 \mathrm{~mm}$, respectively at $866 \mathrm{MHz}$ operating frequency which is too large for the RFID tag. To optimise the size of the tag antenna, the length or the width or both can be reduced simultaneously. In this proposed design, the antenna length is selected to $L=78 \mathrm{~mm}$ and kept constant while simulating. A parameter sweep is performed for width from $40 \mathrm{~mm}$ to $80 \mathrm{~mm}$ with step size of $10 \mathrm{~mm}$ in the Sonnet Lite electromagnetic (EM) simulator. Figure 3 shows the simulated result for the different values of width $(W)$ while keeping the length $(L)$ fixed to $78 \mathrm{~mm}$. When $W=50 \mathrm{~mm}$, it meets the design requirements of the proposed antenna. Therefore, the width of the proposed antenna is selected as $50 \mathrm{~mm}$.

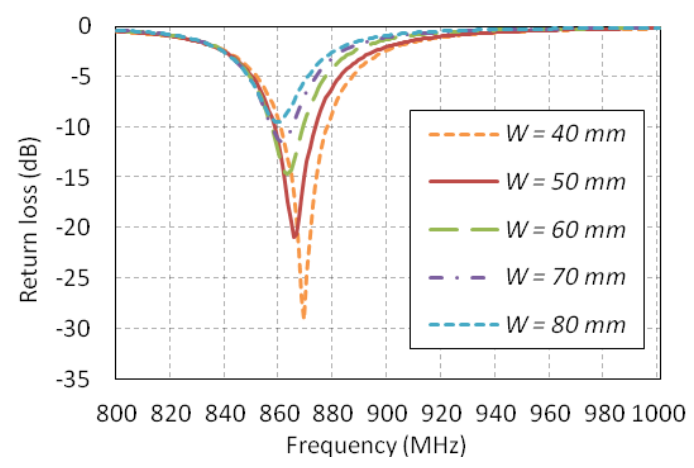

Figure 3: Simulated result of the proposed antenna for different values of $W$ while keeping $L$ fixed to $78 \mathrm{~mm}$.

\subsubsection{Fine Tuning of the Resonance Frequency of with help of Windows}

As mentioned in section 2.4, two small slots on the radiating element known as windows are used for the fine tuning of the proposed antenna to the desired resonance frequency. Figure 4 shows the return loss curve for different values of window length $\left(L_{\mathrm{w}}\right)$ while keeping window width $\left(W_{\mathrm{w}}\right)=2 \mathrm{~mm}$ and other parameters of the proposed antenna at constant. When $L_{\mathrm{w}}$ varies from $2 \mathrm{~mm}$ to $10 \mathrm{~mm}$, the resonance frequency of the proposed antenna varies 867 $\mathrm{MHz}$ to $864 \mathrm{MHz}$, respectively. This clearly shows that without changing other parameter of the proposed antenna, the resonance of the antenna can be tuned to desired operating frequency by varying the length of the two small slots on the radiating element. When $L_{\mathrm{w}}=6 \mathrm{~mm}$, the resonance frequency is $866 \mathrm{MHz}$ and it meets the design requirement of the proposed antenna.

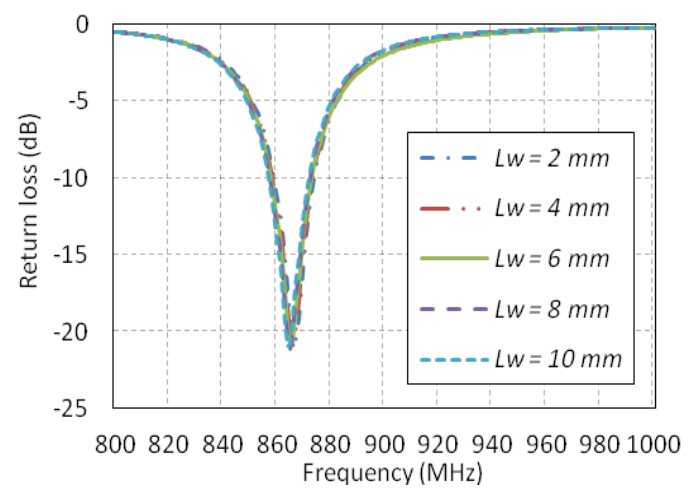

Figure 4: The return loss curve for the different values of window length $\left(L_{\mathrm{w}}\right)$ while keeping window width $\left(W_{\mathrm{w}}\right)=2 \mathrm{~mm}$ and other parameters of the proposed antenna at constant.

\subsubsection{Return Loss Curve of the Proposed Antenna}

Figure 5 shows the return loss at $866 \mathrm{MHz}$ resonance frequency for selected $L=78 \mathrm{~mm}$ and $W=50 \mathrm{~mm}$. The Sonnet and AWR simulation results show strong agreement. The minimum value of the simulated return loss $\left(S_{11}\right)$ at the resonance frequency from the Sonnet is $-21.03 \mathrm{~dB}$. It is clear that satisfactory impedance matching is obtained. The halfpower bandwidth (return loss $<-3 \mathrm{~dB}$ ) is $46 \mathrm{MHz}(5.31 \%)$, from $843.50 \mathrm{MHz}$ to $889.50 \mathrm{MHz}$. The simulated $<-10 \mathrm{~dB}$ bandwidth of the proposed tag antenna is $15 \mathrm{MHz}(1.73 \%)$, from $858.50 \mathrm{MHz}$ to $873.50 \mathrm{MHz}$. The bandwidth satisfies the desired frequency range i.e. from $865 \mathrm{MHz}$ to $867 \mathrm{MHz}$ as well as the minimum bandwidth requirement $(500 \mathrm{kHz})$ of the ISO/IEC 18000-7 standard.

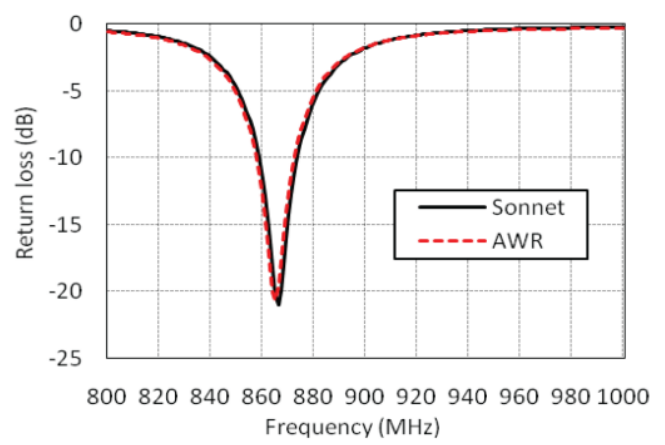

Figure 5: Simulated return loss curve of the proposed micro-strip patch antenna. 


\subsubsection{Input Impedance Curve of the Proposed Antenna}

Figure 6 and Figure 7 show the input resistance and input reactance, respectively against UHF frequency of the proposed micro-strip patch antenna. Both the Sonnet and AWR simulation are closely matched. The impedance characteristics show that the input resistance and reactance of the antenna are complex conjugately matched to the chip input impedance of $Z_{C}=(31-j 212) \Omega$. It is clearly shown in Figure 6 that the proposed antenna input resistance $\left(R_{\mathrm{A}}\right)$ is 31 $\Omega$ at $866 \mathrm{MHz}$ operating frequency. On the other hand, the input reactance $\left(X_{\mathrm{A}}\right)$ is given by the average value of $X_{\mathrm{A}-\max }$ (maximum peak reactance) by $X_{\mathrm{A}-\min }$ (minimum peak reactance). From simulation results, the calculated average input reactance is $200 \Omega$ which is very close to the chip input reactance. The input resistance matching between the antenna and the chip at the resonance frequency can be tuned by adjusting the rectangular slot length $L_{S}$ and the inset feeding line $L_{\mathrm{fb}}$ as shown in Figure 8. Similarly, the input reactance matching between the antenna and chip at the resonance frequency can be tuned by adjusting the rectangular slot $W_{\mathrm{s}}$, the distance of feeding line $L_{\mathrm{fb}}$ and feeding line width $W_{\mathrm{f}}$.

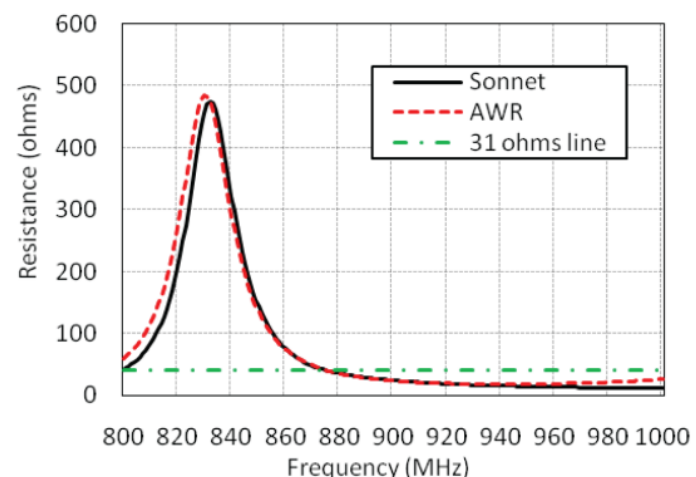

Figure 6: Simulated input resistance against UHF frequency of the proposed micro-strip patch antenna.

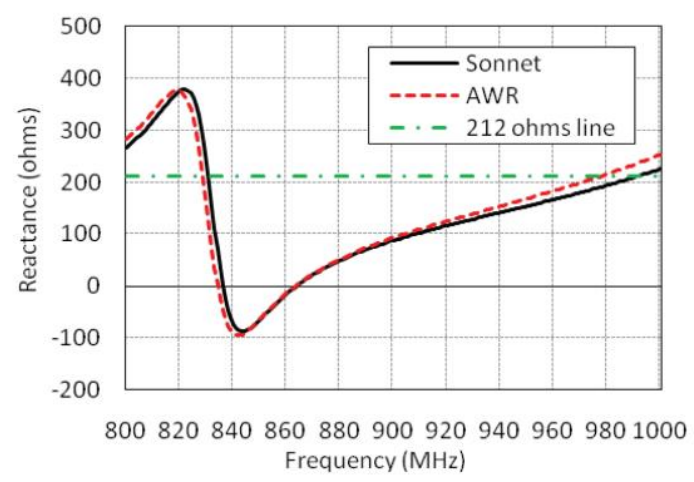

Figure 7: Simulated input reactance against UHF frequency of the proposed micro-strip patch antenna.

\subsubsection{Radiation Patterns of the Proposed Antenna}

Figure 9 shows the simulated radiation patterns of the proposed micro-strip patch antenna at $866 \mathrm{MHz}$ in the Eplane ( $\mathrm{x}-\mathrm{z}$ plane). Figure 10 shows the simulated radiation patterns of the proposed micro-strip patch antenna at 866 $\mathrm{MHz}$ in the H-plane (x-y plane). At zero degree, E-plane has a maximum radiation of $3.28 \mathrm{~dB}$ and $\mathrm{H}$-plane has maximum radiation of $3.29 \mathrm{~dB}$. The radiation patterns are almost omnidirectional in the E-plane and almost bidirectional in the H-plane.

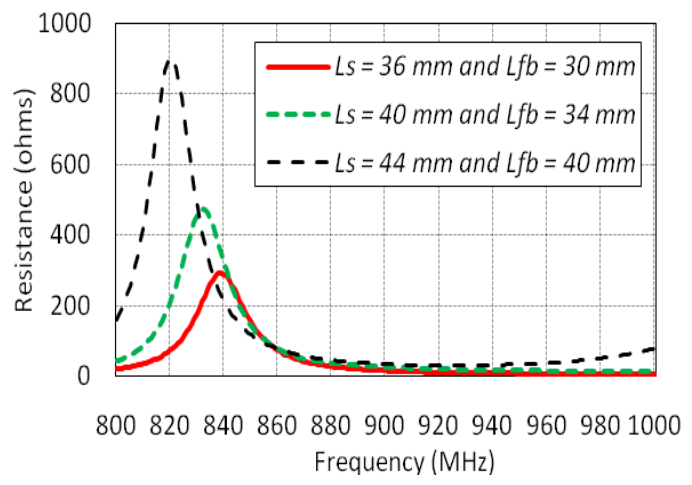

Figure 8: Simulated input resistance of the proposed micro-strip patch antenna for different values of slot length, $L_{\mathrm{s}}$ and feeding line, $L_{\mathrm{fb}}$ while keeping other antenna parameters same.

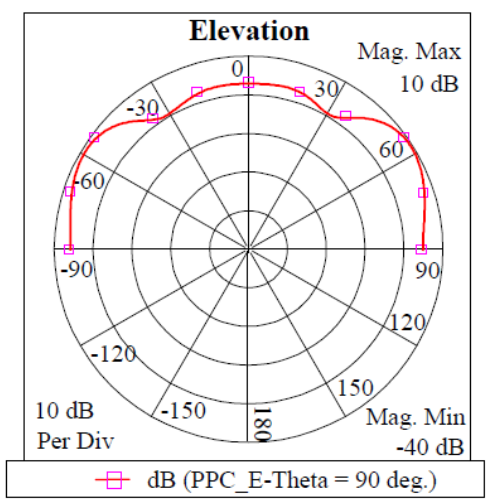

Figure 9: Simulated radiation patterns at $866 \mathrm{MHz}$ for the proposed microstrip patch antenna in E-plane.

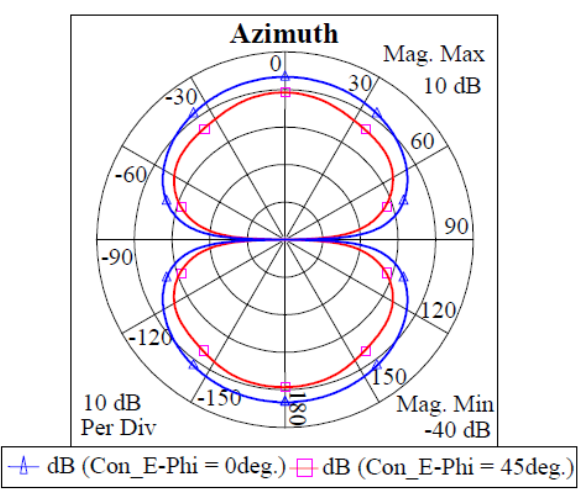

Figure 10: Simulated radiation patterns at $866 \mathrm{MHz}$ for the proposed microstrip patch antenna in H-plane.

\subsubsection{Effect of the Ground Plane Size on the Performance of the Proposed Antenna}

The antenna is designed on the infinite ground plane in both the Sonnet and AWR EM simulators. However, in a real world application, the infinite ground plane is replaced by the finite ground plane and it can show some effects on the return loss and on the resonance frequency of the micro-strip patch antenna $[11,16]$. To investigate this effect, three different ground planes of sizes $86 \mathrm{~mm} \times 58 \mathrm{~mm} \times 0.0358 \mathrm{~mm}$, $100 \mathrm{~mm} \times 100 \mathrm{~mm} \times 0.0358 \mathrm{~mm}$, and infinite one are considered. Figure 11 shows the simulated return loss against UHF frequency of the proposed micro-strip patch antenna while keeping other parameters of the proposed tag 
antenna the same. The change in bandwidth is evaluated based on the half power $(<-3 \mathrm{~dB})$ and $<-10 \mathrm{~dB}$ return loss bandwidth. There is not much effect on the bandwidths but there are shifts in the resonance frequencies. However, the entire range of shifts in the resonance frequencies is within the desired goal of the proposed tag antenna.

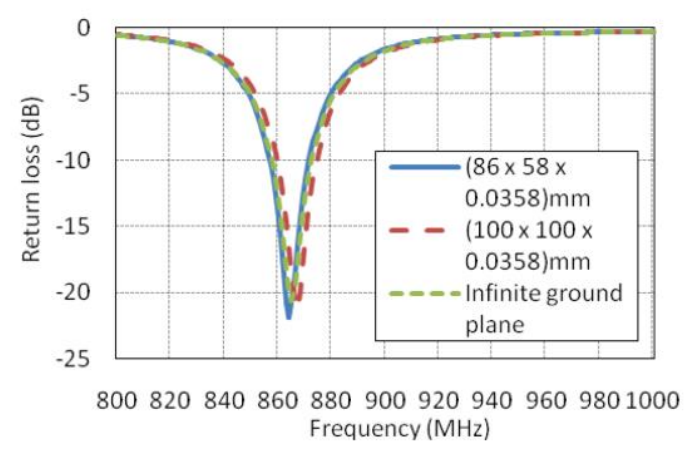

Figure 11: Simulated results return loss of the proposed micro-strip patch antenna for different size of the ground plane.

\section{PROTYPE DEVELOPMENT AND READING RANGE MEASUREMENT}

The reading range is a very important performance parameter of the RFID tag. The RFID tag is considered to be better if the reading range is longer. In order to investigate the effects of the metallic objects on the reading range of the proposed micro-strip patch antenna, a prototype is fabricated.

\subsection{Prototyping}

The prototype micro-strip patch antenna is fabricated using the KELAN PCB discussed in section 2. First, the FR4 PCB board is cut into required size. Then, the micro-strip patch antenna is fabricated using the Milling machine. Next, the Alien Higgs-3 is attached to the prototype micro-strip patch antenna. Once the chip is attached to the tag antenna, it is called as an inlay or a tag. Figure 12 shows the prototype tag and the Alien squiggle tag [25].

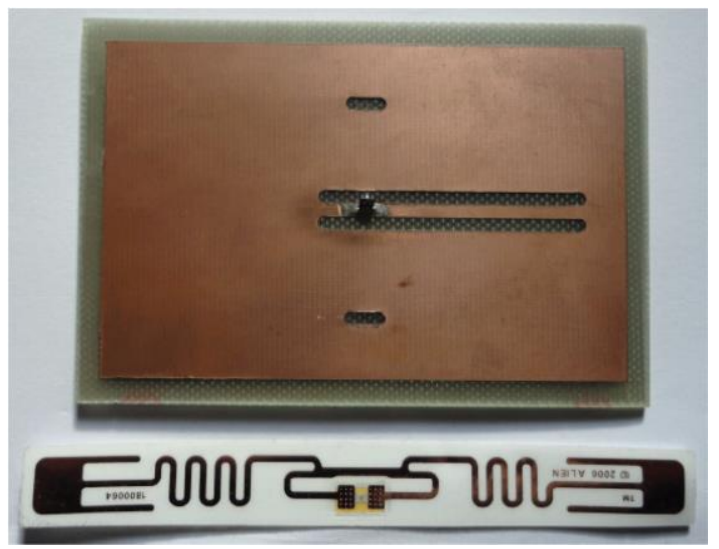

Figure 12: The prototype tag (above) and Alien (ALN-9640) squiggle tag (below).

\subsection{Experimentation of the Reading Range Measurement}

The Alien RFID reader (model no. ALR-9900-EMA) [26] with output power of $31.6 \mathrm{dBm}$ (equivalent to 2 watts effective radiated power, ERP) and a circular polarised reader antenna that operates at $866 \mathrm{MHz}$ is used in the measurement.
Figure 13 shows the reading range measurement set-up. The reading range of the prototype tag is compared with the Alien squiggle tag (model no. ALN-9640), a commercial passive UHF RFID tag manufactured by the Alien Technology.

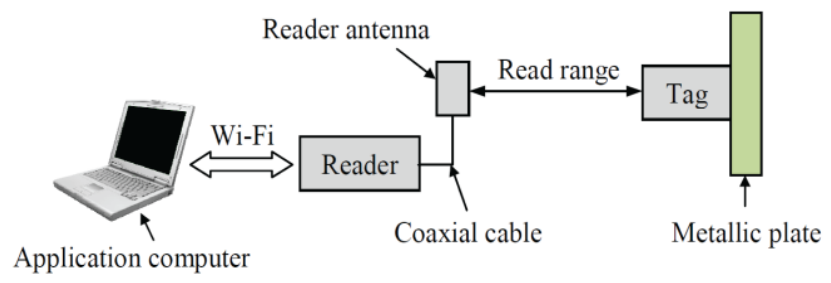

Figure 13: Reading range measurement set-up.

The reading range of the prototype tag is measured for two cases - the maximum reading range and the effective reading range. The maximum reading range measurement for the prototype tag is performed in the outdoor environment which gives enough space to move the prototype tag from the reader antenna and the results are given in Table 1 .

In this experimentation, the reader antenna is fixed on the wall and faces towards the open space to avoid interference from the surrounding environment. It is measured in two scenarios. In the first scenario, the maximum reading range of the Alien tag and the prototype tag are measured in the free space. In the second scenario, the tags are attached onto a $150 \mathrm{~mm} \times 150 \mathrm{~mm}$ Aluminium plate and the reading range is measured. The maximum reading range is defined as the maximum line-of-sight distance between the reader antenna and the tag where the tag is continuously read for a minimum of one minute.

Table 1: Case 1 - outdoor environment and maximum reading ranges with and without metal plate.

\begin{tabular}{|l|l|c|}
\hline \multirow{2}{*}{ Scenario } & Tag & $\begin{array}{l}\text { Maximum reading range } \\
\text { (in metre) }\end{array}$ \\
\hline \multirow{2}{*}{ On cardboard } & Alien squiggle tag & $>5$ \\
\cline { 2 - 3 } & The prototype tag & 4.5 \\
\hline \multirow{2}{*}{$\begin{array}{l}\text { On Aluminium plate } \\
(150 \mathrm{~mm} \times 150 \mathrm{~mm})\end{array}$} & Alien squiggle tag & 0 \\
\cline { 2 - 3 } & The prototype tag & 4.5 \\
\hline
\end{tabular}

The effective reading range measurement of the tags is performed in an indoor environment to observe the effects of signal disturbances from other electronic devices near the reader. The photograph of the effective reading range measurement set-up is shown in Figure 14. In this experimentation, the reader antenna is mounted on a stand which is erected below the room ceiling. The read antenna is faced downward to the floor level at the height of $1.91 \mathrm{~m}$. The results are given in Table 2 .

In this experimentation, the tag is attached onto cardboard or Aluminium plate and is moved in several horizontal and vertical directions with respective to the reader antenna axis and the effective reading range is measured. The effective reading range is defined as the distance between the reader antenna and the tag where the tag is continuously read at any time without any fluctuation in the reading signal. 


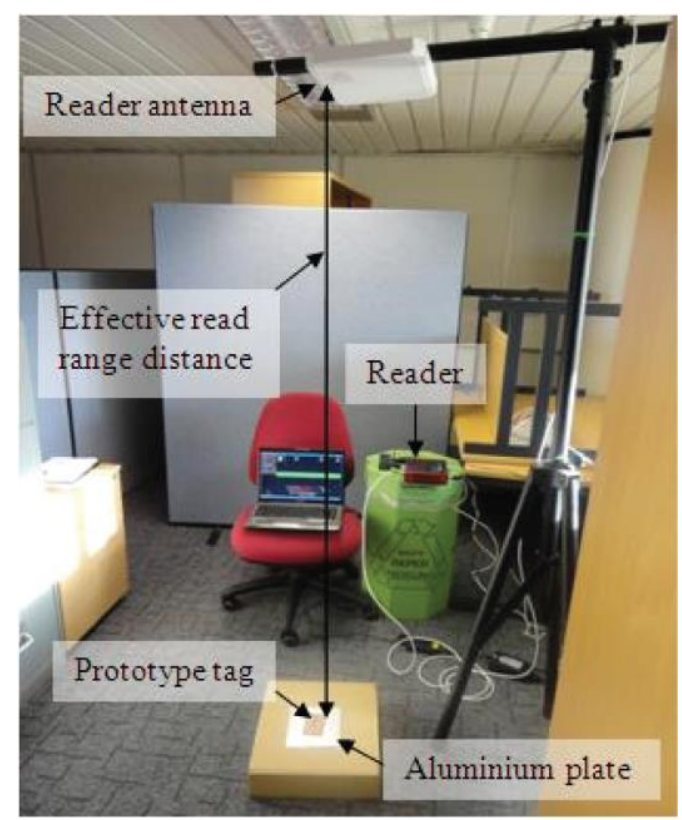

Figure 14: The photograph of effective reading range set-up.

Table 2: Case 2 - indoor environment and effective reading range with and without metal plate.

\begin{tabular}{|l|l|c|}
\hline Scenario & Tag & $\begin{array}{l}\text { Effective reading range } \\
\text { (in metre) }\end{array}$ \\
\hline \multirow{2}{*}{ On cardboard } & Alien squiggle tag & $>5$ \\
\cline { 2 - 3 } & The prototype tag & 1.07 \\
\hline \multirow{2}{*}{$\begin{array}{l}\text { On Aluminium plate } \\
(150 \mathrm{~mm} \times 150 \mathrm{~mm})\end{array}$} & Alien squiggle tag & 0 \\
\cline { 2 - 3 } & The prototype tag & 1.89 \\
\hline
\end{tabular}

From the experimentation, it is observed that the Alien squiggle tag exhibits a longer reading range than the prototype when it is attached to the cardboard. However, the Alien squiggle tag does not work at all when it is attached directly on the metallic surface or on human skin. On the other hand, the prototype tag works very well on the metallic surface and on human skin.

It is observed that the highest reading range (i.e. maximum reading range) of the proposed tag is $4.5 \mathrm{~m}$ when it is attached to the metallic plate and on the human skin. The effective or reliable reading range of the prototype tag on the metallic plate is $1.89 \mathrm{~m}$. It clearly shows that the prototype tag performs superior on the metallic surface than the Alien squiggle tag. The interesting observation from the experimentation is that the prototype tag works better on the

[1] R. Want, "An introduction to RFID technology," IEEE Pervasive Computing, vol. 5, pp. 25-33, 2006.

[2] K. Finkenzeller, RFID Handbook Fundamentals and Applications in Contactless Smart Cards and Identification. Chichester: John Wiley and Sons Ltd, 2003.

[3] W. Dong-Liang, et al., "A brief survey on current RFID applications," in International Conference on Machine Learning and Cybernetics, 2009, pp. 2330-2335.

[4] K. V. S. Rao, et al., "Antenna design for UHF RFID tags: a review and a practical application," IEEE Transactions on Antennas and Propagation, vol. 53, pp. 3870-3876, 2005.

[5] C. Cho, et al., "Broadband RFID tag antenna with quasi-isotropic radiation pattern," Electronics Letters, vol. 41, pp. 1091-1092, 2005.

[6] D. M. Dobkin and S. M. Weigand, "Environmental effects on RFID tag antennas," in Microwave Symposium Digest, 2005 IEEE MTT-S International, 2005, pp. 135-138. metallic surface than the cardboard. The reliable reading range of the prototype tag for both on the cardboard and on the metallic object tagging is satisfactory for most of the passive RFID applications.

\section{CONCLUSION}

A Micro-strip patch antenna is proposed for the passive UHF RFID tag system and can be used for tagging metallic containers in the UK and European warehouse environment. The proposed antenna is designed to operate at the centre frequency of $866 \mathrm{MHz}$ and is tuneable from $865 \mathrm{MHz}$ to 867 $\mathrm{MHz}$ UHF frequency band. The design is supported by the simulation results. A prototype of the proposed micro-strip patch antenna is fabricated and the reading range is compared with the Alien squiggle tag. It is observed that when the Alien squiggle tag is placed on a metal object or human body, the tag is not read at all even if tag is moved very close to the reader antenna. On the other hand, the maximum reading range of the prototype is $4.5 \mathrm{~m}$ with and without any metallic plate in an outdoor environment. The prototype antenna exhibits a $100 \%$ reliable reading range of $1.07 \mathrm{~m}$ on cardboard and $1.89 \mathrm{~m}$ on a metal plate in an indoor environment. With the help of design, simulation, and implementation results, it is clearly demonstrated that the use of the micro-strip patch antenna for a passive UHF RFID tag can possibly solve the existing problem faced by the passive UHF RFID system for tagging metallic objects. Designing micro-strip patch antenna using paper substrate to reduce overall cost, optimising the micro-strip patch antenna gain and increasing the reading range, conduction of more realistic experimentation from applications point of view and integration of the proposed tag with the readers/antennas (from system point of view or as a product or standardisation) can be considered as future works.

\section{ACKNOWLEDGMENT}

This work was supported by the eLINK (east-west Link for Innovation, Networking, and Knowledge Exchange) project. The authors would like to thank Mr. Stephen Crocker, Director, Sales/Channels EMEA and India, Alien Technology Corp. for supplying the sample Alien Higgs-3s and some passive UHF RFID tags without any charge and Mr. Paul Bentley, Technical Skills Specialist, Staffordshire University for sharing his technical assistance.

\section{REFERENCES}

[7] J. D. Griffin, et al., "RF Tag Antenna Performance on Various Materials Using Radio Link Budgets," Antennas and Wireless Propagation Letters, IEEE, vol. 5, pp. 247-250, 2006.

[8] K. H. Kim, et al., "Fork-shaped RFID tag antenna mountable on metallic surfaces," Electronics Letters, vol. 43, pp. 1400-1402, 2007.

[9] H. W. Son, et al., "Design of wideband RFID tag antenna for metallic surfaces," Electronics Letters, vol. 42, pp. 263-265, 2006.

[10] L. Xu, et al., "UHF RFID tag antenna with broadband characteristic," Electronics Letters, vol. 44, pp. 79-80, 2008.

[11] L. Ukkonen, et al., "Effects of metallic plate size on the performance of microstrip patch-type tag antennas for passive RFID," IEEE Antennas and Wireless Propagation Letters, vol. 4, pp. 410-413, 2005.

[12] C. Horng-Dean and T. Yu-Hung, "Low-Profile Meandered Patch Antennas for RFID Tags Mountable on Metallic Objects," Antennas and Wireless Propagation Letters, IEEE, vol. 9, pp. 118-121, 2010. 
[13] C. Horng-Dean and T. Yu-Hung, "Broadband Capacitively Coupled Patch Antenna for RFID Tag Mountable on Metallic Objects," IEEE Antennas and Wireless Propagation Letters, vol. 9, pp. 489-492, 2010.

[14] L. Mo, et al., "Broadband UHF RFID tag antenna with a pair of U slots mountable on metallic objects," Electronics Letters, vol. 44, pp. 1173-1174, 2008.

[15] K. V. S. Rao, et al., "UHF RFID tag for metal containers," in Microwave Conference Proceedings (APMC), 2010 Asia-Pacific, 2010, pp. 179-182.

[16] M. Hirvonen, et al., "Planar inverted-F antenna for radio frequency identification," Electronics Letters, vol. 40, pp. 848-850, 2004.

[17] H. Kwon and B. Lee, "Compact slotted planar inverted-F RFID tag mountable on metallic objects," Electronics Letters, vol. 41, pp. 1308-1310, 2005.

[18] C. Horng-Dean and T. Yu-Hung, "Low-Profile PIFA Array Antennas for UHF Band RFID Tags Mountable on Metallic Objects," IEEE Transactions on Antennas and Propagation, vol. 58, pp. 1087-1092, 2010.

[19] L. Ukkonen, et al., "Operability of Folded Microstrip Patch-Type Tag Antenna in the UHF RFID Bands Within 865-928 MHz," Antennas and Wireless Propagation Letters, IEEE, vol. 5, pp. 414-417, 2006.
[20] Alien. (2010). RFID ICs [Online]. Available: http://www.alientechnology.com/docs/products/DS_H3.pdf [Accessed: 25 Dec. 2010]

[21] Farnell. (2010). KELAN-PCB [Online]. Available: http://uk.farnell.com/kelan/149059/pcb-plain-d-s220x100mm/dp/149059?Ntt=149059 [Accessed: 23 November 2010]

[22] C. A. Balanis, Antenna theory : analysis and design, 3rd ed. ed. Hoboken, N.J.: [Great Britain] : Wiley-Interscience, 2005.

[23] C. Blair and J. C. Rautio, "RFID design using EM analysis," in Applications and Technology Conference (LISAT), 2010 Long Island Systems, 2010, pp. 1-6.

[24] AWR. (na). Microstrip Patch Antenna [Online]. Available: https://awrcorp.com/download/faq/english/examples/Microstrip_Patc h_Antenna.aspx [Accessed: 28 January 2011]

[25] Alien. (2010). ALN-9640 Squiggle Inlay [Online]. Available: http://www.alientechnology.com/docs/products/DS_ALN_9640.pdf [Accessed: 15 June 2010]

[26] Alien. (2010). ALR-9900+EMA Enterprise RFID reader [Online]. Available: http://www.alientechnology.com/docs/products/DS_ALR_9900+EM A.pdf [Accessed: 10 March 2011] 